\title{
Esofagectomia transhiatal laparoscópica para o tratamento do megaesôfago avançado - análise de 60 casos
}

\section{Laparoscopic transhiatal esophagectomy for the treatment of advanced megaesophagus. An analysis of 60 cases}

\author{
Eduardo Crema, TCBC-MG; lara Beatriz Prata Ribeiro²; Renato Costa Sousa33; Júverson Alves Terra Júnior ${ }^{4}$; \\ Bruna Ferrante Silva ${ }^{2}$; Alex Augusto Silva ${ }^{5}$; Athos Vargas Silva 3
}

\section{R E S U M O}

\begin{abstract}
Objetivo: Utilizamos esta pesquisa para estudar e demonstrar que a esofagectomia subtotal através do acesso laparoscópico e transmediastinal para o preparo do estômago, dissecção do esôfago, abdominal e torácico, e cervicotomia esquerda para retirada da peça e anastomose esôfago-gástrica é facultativa e segura no tratamento do megaesôfago avançado. Métodos: Foram realizadas 60 esofagectomias transhiatais por laparoscopia de setembro de 1996 até dezembro de 2006 (10 casos com preservação dos nervos vagos). A idade média dos pacientes foi 56,4 anos (18 - 76) e antes da operação foram submetidos à sorologia para T. cruzi, esofagograma, endoscopia digestiva de alta resolução, eletromanometria, ultrassom de vesícula biliar e pHmetria de 24 horas, avaliação nutricional, fisioterapia respiratória e suporte nutricional através de sonda nasoenteral. As indicações para o tratamento cirúrgico foram: megaesôfago avançado, diagnosticado radiologicamente e manometricamente, recidiva de megaesôfago após operação envolvendo a junção esôfago-gástrica e associação com disfagia acentuada e/ou neoplasia. O acompanhamento foi de 6 a 118 meses. Resultados: Não houve mortalidade, o tempo médio das operações foi de 160 minutos $(110$ - 325) e houve melhora de todos os parâmetros avaliados. Doze dos 60 pacientes (20\%) apresentaram complicações. Ocorreram oito casos de hemopneumotórax (13,34\%), três casos de estase gástrica (5\%), quatro casos de fístula cervical $(6,67 \%)$ com resolução clínica e nove casos de disfonia (15\%). Conclusão: Os resultados observados na esofagectomia transhiatal laparoscópica foram satisfatórios. Demonstraram que a técnica é segura e traz excelentes resultados pós-operatórios.
\end{abstract}

Descritores: megaesôfago; laparoscopia; esofagectomia.

\section{INTRODUÇÃO}

$\mathrm{D}$ efine-se como megaesôfago avançado, do ponto de vista radiológico, quando há um alongamento do esôfago e mudança do eixo da deglutição em relação à coluna vertebral (dolicomegaesôfago), e do ponto de vista funcional considera-se megaesôfago avançado quando, ao exame manométrico, observa-se ondas de contração do esôfago com amplitude menor que $20 \mathrm{mmHg}$, qualquer que seja o calibre esofageano ${ }^{1}$.

Nas formas avançadas observa-se que o esôfago transforma-se em uma bolsa inerte, quase sempre com estase em seu interior com conseqüentes alterações crônicas da parede que podem apresentar displasias e/ou neoplasia em taxa de até 140 vezes mais freqüentes que a população geral ${ }^{2}$. A permanência crônica de estase provoca proliferação bacteriana e mudança da flora intra luminal do esôfago ${ }^{3}$, o que se agrava ainda mais quando ocorre bronco aspiração. A produção de ácidos fracos muda o pH esofagiano e provoca aumento da prevalência de HPV ${ }^{4}$, que em outros sítios do organismo associa-se a maior incidência de neoplasia maligna ${ }^{5-7}$.

Com base nessas considerações e com os maus resultados apresentados com as técnicas cirúrgicas que abordaram a junção esofagogástrica na forma avançada da doença, não nos resta outra opção que praticar a esofagectomia subtotal com ressecção do segmento abdominal e torácico do esôfago, preservando a porção cervical, segmento este que apresenta musculatura predominante estriada, portanto sem plexos mioentéricos de Auerbach, logo sem comprometimento pela doença de Chagas. Com isso pode-se dizer que a esofagectomia subtotal cura a esofagopatia chagásica.

Historicamente Câmara Lopes e Ferreira Santos praticavam para o tratamento cirúrgico do megaesôfago avançado a esofagectomia subtotal por meio de cervicotomia, toracotomia direita e laparotomia ${ }^{8}$. Eugênio Bueno e Pinotti ${ }^{9,10}$ propuseram a ressecção do esôfago atra-

Trabalho realizado no Departamento de Cirurgia do Aparelho Digestivo da Universidade Federal do Triângulo Mineiro, Uberaba, Minas Gerais, Brasil.

1. Professor Titular da Disciplina de Cirurgia do Aparelho Digestivo da Universidade Federal do Triângulo Mineiro - UFTM - MG-BR; 2. Residente da Disciplina de Cirurgia do Aparelho Digestivo da UFTM - MG-BR; 3. Médico do Serviço de Cirurgia do Aparelho Digestivo da UFTM - MG-BR; 4. Professor Assistente Mestre do Departamento de Cirurgia do Aparelho Digestivo da UFTM - MG-BR; 5. Professor Adjunto do Departamento de Cirurgia do Aparelho Digestivo da UFTM - MG-BR. 
vés de laparotomia e cervicotomia. De Paula ${ }^{11}$ e Crema ${ }^{12}$ propuseram a esofagectomia subtotal através do acesso laparoscópico e transmediastinal para o preparo do estômago, dissecção do esôfago abdominal e torácico e cervicotomia esquerda para retirada da peça e anastomose esôfago-gástrica, técnica esta em nosso meio empregada nos serviços de referência para o tratamento do megaesôfago avançado.

O objetivo deste trabalho é demonstrar que a esofagectomia subtotal através do acesso laparoscópico é factível e segura para o tratamento do megaesôfago avançado.

\section{MÉTODOS}

Foram realizadas 60 esofagectomias transhiatais por laparoscopia de setembro de 1996 até dezembro de 2006, sendo que os últimos 10 casos foram feitos com preservação dos nervos vagos. Destes, 53 (88,33\%) em portadores de mega chagásico e sete $(11,67 \%)$ mega idiopático, a idade média foi de 56,4 anos (18-76 anos), sendo 34 do sexo masculino e 26 do sexo feminino. Vinte e oito pacientes $(46,67 \%)$ tinham sido submetidos anteriormente a um ou mais procedimentos cirúrgicos na transição esôfago-gástrico: dilatação (23), cardiomiotomia de Heller (25), cirurgia de THAL (três), quatro pacientes $(6,67 \%)$ haviam sido submetidos a cirurgia de mega colo (Duhamel).

Todos os pacientes foram submetidos no pré-operatório à sorologia do $T$. cruzi, exame contrastado do esôfago (ECE), endoscopia digestiva alta, eletromanometria e pH-metria de 24 horas e ultrassonografia da vesícula biliar.

A avaliação nutricional foi realizada no pré e no pós operatório em todos os pacientes e constituiu de avaliação: antropométrica (peso, altura, circunferência da musculatura do braço, prega cutânea e índice creatinina $x$ altura), bioquímica (proteínas totais, albumina e transferrina) e imunológica (linfócitos totais e PPD - Derivado Protéico da Tuberculina Purificada).

Todos os pacientes foram submetidos a preparo pré-operatório ambulatorial por 7 a 21 dias, que constituiu de fisioterapia respiratória e suporte nutricional enteral $(1,5$ g proteína/kg/dia), por meio de uma sonda nasoenteral (SNE) posicionada no estômago.

Todos os pacientes receberam informações sobre o procedimento cirúrgico realizado e o protocolo da pesquisa foi aprovado pelo Comitê de Ética Médica de Pesquisa em Humanos (Universidade Federal do Triângulo Mineiro, Uberaba, Brasil).

Consideramos como indicações de esofagectomia subtotal laparoscópica transhiatal: o megaesôfago avançado radiológico (Grau IV); megaesôfago avançado funcionalmente (aperistalse, amplitude de contração do corpo menor que $20 \mathrm{mmHg}$ ), recidiva do megaesôfago após operações sobre a junção esofagogástrica; associação de displasia grave e/ou neoplasia associada com megaesôfago.

\section{Preparo pré-operatório}

A avaliação clínica em especial cardiológica, pulmonar e nutricional, deve ser realizada rotineiramente, porque habitualmente possuem comorbidades e no momento em que se apresentam para o tratamento encontram-se desnutridos. A avaliação do tempo de esvaziamento gástrico pela cintilografia com $\mathrm{Tc}^{99}$ e com contraste baritado introduzido pela sonda no estômago é importante para afastar a associação com o mega-estômago que ocorre em nossa casuística em $8 \%$ dos pacientes com megaesôfago.

A ultrassonografia abdominal também é útil para o diagnóstico de colelitíase que está associada ao megaesôfago em taxas que variam de 14 a $26 \%{ }^{13,14}$.

Na véspera da operação, passa-se uma sonda oroesofágica de Fouchet ou de Levine grossa e praticase a limpeza mecânica do esôfago com solução salina a $0,9 \%$.

\section{Técnica Cirúrgica}

O posicionamento do doente é o mesmo empregado para a esofagocardiomiotomia laparoscópica. Paciente em litotomia com membros inferiores estendidos, afastados e adequadamente amparados em perneira apropriada, ficando o cirurgião entre as pernas, e os auxiliares à esquerda do paciente (câmera e apresentação). O monitor, quando único, posiciona-se na cabeceira a direita da mesa operatória.

Utiliza-se cinco punções: a) trocáter de $10 \mathrm{~mm}$ acima da cicatriz umbilical, aproximadamente a $15 \mathrm{~cm}$ do apêndice xifóide ( ótica de 30 graus); b) trocáter de $10 \mathrm{~mm}$ subcostal esquerda linha hemi-clavicular ( mão direita do cirurgião); c) trocáter $5 \mathrm{~mm}$ subcostal direita, linha hemi-clavicular (mão esquerda do cirurgião); d) trocáter de $5 \mathrm{~mm}$ linha média, sub-xifóide ( auxiliar afastando o lobo esquerdo do fígado); e) trocáter $5 \mathrm{~cm} \mathrm{a}$ esquerda da cicatriz (auxiliar tracionando a transição e esôfago) sendo suficiente o de $5 \mathrm{~mm}$, embora alguns autores prefiram o de $10 \mathrm{~mm}$ para a utilização de pinça -tipo Babcok (Figura 1).

Quando existe associação de colelitíase a $5^{\text {a }}$.porta de entrada e, pode ser colocada à direita e facilita a apresentação da vesícula biliar no tempo da colecistectomia.

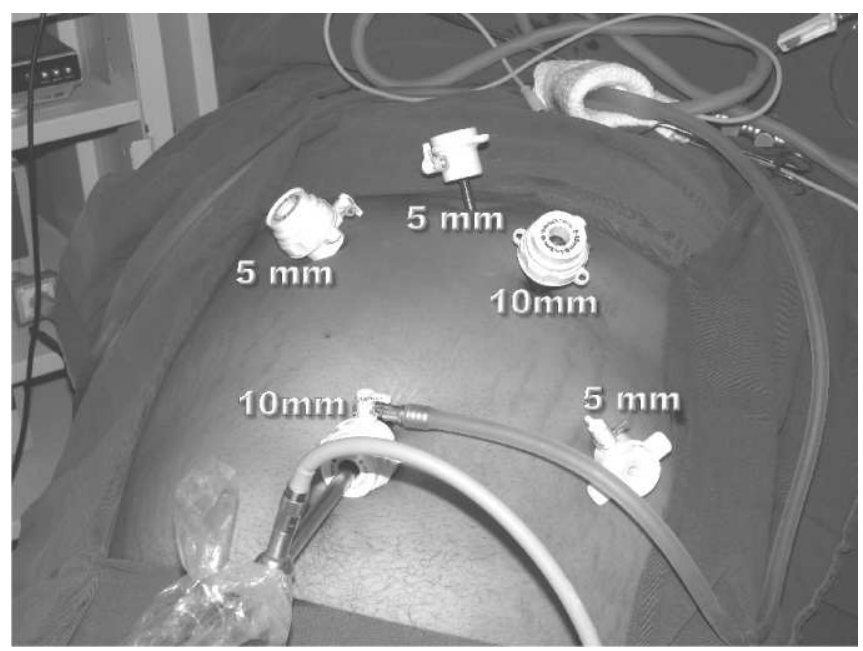

Figura 1 - Nota-se a posição dos trocáteres para a realização da esofagectomia subtotal. 
Com o pneumoperitôneo de $12 \mathrm{mmHg}$ inicia-se o procedimento que consiste na abertura da membrana frenoesofágica e do omento maior, dando acesso ao ramo direito do pilar direito do diafragma, a partir deste ponto libera-se o tecido peri-esofagiano ao redor do esôfago terminal, isolando-se o esôfago com dissecção da transição esofago-gástrica reparando o esôfago abdominal com dreno de Penrose ou com afastador flexível (endoflex). Identifica-se o tronco vagal anterior e posterior, o seu isolamento e a dissecção dos troncos vagais até abaixo da transição esôfago-gástrica é importante quando opta-se pela preservação dos nervos vagos durante a ressecção do esôfago. (Figuras $2 \mathrm{~A}$ e B).

Neste momento prossegue-se a dissecção sob visão direta do corpo do esôfago com identificação das pleuras, do pericárdio, da veia ázigos e dos troncos vagais em toda extensão torácica A hemostasia é realizada com cauterização monopolar e/ou clipagem dos ramos esofageanos maiores ou preferencialmente com o emprego do bisturi ultra-sônico. É importante que o plano cirúrgico seja próximo ao esôfago evitando-se com isso lesão das pleuras e de estruturas mediastinais.

Para melhor acesso ao mediastino no tempo cirúrgico da dissecção do esôfago torácico praticamos transecção mediana do diafragma e posicionamos a mesa cirúrgica em posição de Trendelenburg como na abordagem cervical abdominal em operação aberta.

Após completada a dissecção do esôfago abdominal e torácico inicia-se o preparo do estômago com liberação da grande curvatura. Pode-se empregar o eletrocautério monopolar ou bipolar ou, preferencialmente, o bisturi harmônico para secção dos vasos curtos, e do epiplon gastrocólico. Para ligadura da artéria e veia gastroepiplóica e da artéria e veia gástrica esquerda utiliza-se clipagem dupla, preservando a arcada da grande e pequena curvatura.

Não realizamos piloroplastia no tratamento cirúrgico do megaesôfago avançado quando se trata de esofagopatia chagásica. Completado o preparo do estô- mago, pratica-se por meio da cervicotomia esquerda a dissecção do esôfago cervical. Por tração delicada da peça cirúrgica, exterioriza-se o esôfago e a parte proximal do estômago na região cervical, efetua-se a secção da transição esofagogástrica com auxílio de grampeador linear cortante de carga verde.

Durante a tração cervical do esôfago previamente dissecado deve-se acompanhar a passagem do esôfago e do estômago pelo mediastino sob visão direta com auxílio da ótica posicionada no mediastino inferior.

A anastomose esôfagogástrica é feita com sutura contínua manual com fio monofilamentado de polipropileno em plano único.

Posiciona-se a sonda naso-enteral no duodeno, quando possível, ou no antro gástrico, que receberá dieta enteral, como descrito para o pré-operatório, 24 horas após o procedimento cirúrgico. Não empregamos drenagem cervical ou abdominal.

É de relevância salientar que a dissecção do vago anterior e posterior deve ser realizada antes da dissecção do esôfago e do preparo do estômago para que no tempo cervical não haja a secção inadvertida dos troncos vagais.

A não realização da piloroplastia nos pacientes portadores de esofagopatia chagásica que não apresentam megaestômago, evita o refluxo do duodeno para o estômago agora posicionado no mediastino posterior, região de pressão negativa.

Outro fato importante: a anastomose esofagogástrica deve permanecer na região cervical, que apresenta pressão positiva, evitando com isso o refluxo de líquido gástrico para o interior do esôfago com conseqüente esofagite. Esta pode ocorrer quando a anastomose fica em situação intratorácica.

A utilização do estômago total como órgão de plastia justifica-se pela manutenção de melhor vascularização do fundo gástrico pela não interrupção da rede vascular submucosa do corpo e fundo gástrico mantida com a comunicação vascular da arcada de pequena e grande curvatura.
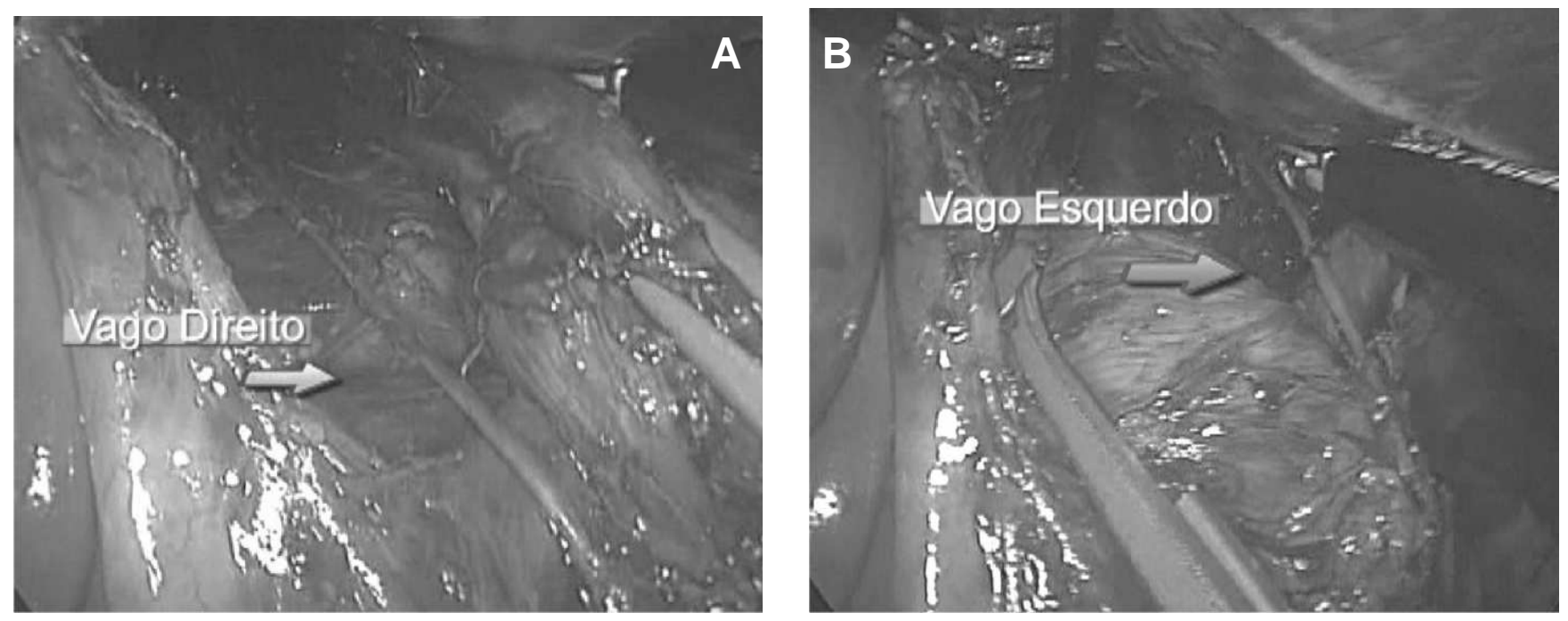

Figura $2 A$ e $B-$

Nota-se o segmento esofágico completamente dissecado, em detalhe os troncos vagais direito e esquerdo. 


\section{RESULTADOS}

Não houve mortalidade. O tempo médio de operação foi de 160 minutos (110 - 325) e notou-se melhora de todos os parâmetros avaliados. Somente cinco pacientes (8,34\%) necessitaram de assistência ventilatória no período pós-operatório e três necessitaram de transfusão sangüínea durante ou após a cirurgia. A taxa de complicação foi de $40 \%$ (24 complicações em 12 pacientes (20\%), oito casos de hemopneumotórax (13,34\%) que necessitou drenagem de tórax no período per ou pós-operatório, ocorreu estase gástrica em três casos (5\%), fístula cervical em quatro casos $(6,67 \%)$ com resolução clínica com suporte nutricional enteral exclusivo e drenagem cervical pela retirada de pontos de incisão cervical, disfonia em nove casos $(15 \%)$.

As complicações tardias ocorreram em sete casos $(11,67 \%)$, três pacientes (5\%) apresentaram disfonia que melhorou somente após três meses e disfagia em dois casos (3,34\%) que necessitaram de dilatação endoscópica. As complicações que necessitaram de tratamento cirúrgico foram dois pacientes (3,34\%) com estase gástrica, os quais foram submetidos a piloroplastia por laparoscopia e um caso de abdome agudo obstrutivo que ocorreu 19 meses após a esofagectomia por encarceramento de um segmento de cólon transverso no hiato mediastinal previamente aberto durante a esofagectomia. O exame histopatológico e reação em cadeia da polimerase (PCR) para T. cruzi na peça cirúrgica comprovaram a esofagopatia chagásica em 53 casos $(88,34 \%)$ e idiopática em sete casos $(11,67 \%)$. Os casos com neoplasia associada diagnosticada no pré-operatório ou na peça cirúrgica foram excluídos desta casuística.

Realizou-se o exame contrastado de coto esofágico, estômago e duodeno no décimo dia, três meses e um ano de pós-operatório, que revelou a anastomose esôfago-gástrica na região cervical. A endoscopia realizada três meses e um ano após o tratamento cirúrgico detectou dois casos (3,34\%) de esofagite de coto esofágico, apesar do exame manométrico demonstrar que a anastomose encontrava-se em região de pressão elevada ( $P$ ), e a pHmetria de 24 horas, com sensor de $\mathrm{pH}$ posicionado $2 \mathrm{~cm}$ acima da anastomose esôfago-gástrica, não detectar refluxo ácido em nenhum paciente.

No período de acompanhamento que foi de 6 a 118 meses, os achados clínicos, radiológicos, endoscópicos e pHmétricos demonstraram que os resultados do procedimento são satisfatórios e encorajadores.

\section{DISCUSSÃO}

A técnica mais apropriada para o tratamento do megaesôfago baseia-se na fase da esofagopatia, que quando encontram-se em fase não avançada, a cardiomiotomia associada à válvula anti-refluxo parcial tem se apresentado como a melhor opção cirúrgica.

Na fase avançada da esofagopatia, pelo exame contrastado, é caracterizada por apresentar calibre de esôfago de $10 \mathrm{~cm}$ e/ou tortuosidade do esôfago com a mudança do eixo de deglutição (dolicoesôfago) ${ }^{15,16}$.

Do ponto de vista funcional o megaesôfago pode ser caracterizado pelo achado do exame manométrico de ondas de contração do corpo de amplitude menor que $20 \mathrm{mmHg}$. Observou-se em trabalhos anteriores que todos os pacientes com megaesôfago avançado radiológico apresentavam ondas peristálticas menores que $20 \mathrm{mmHg}^{1}$, já entre os portadores de mega não avançado radiológico, 38,4\% dos casos apresentavam ondas de baixa amplitude, portanto estes foram classificados como megaesôfago avançado funcionalmente.

O tratamento cirúrgico dessa forma de doença apresenta resultados insatisfatórios com o emprego de qualquer das técnicas sobre a função esôfago gástrica ${ }^{17}$, portanto a esofagectomia subtotal com a retirada desta bolsa inerte, repleta de líquido de estase rico em enterobactérias ${ }^{3}$ e com importantes alterações mucosas (esofagite de estase, displasia e/ou neoplasia) ${ }^{18}$.

Com o advento de abordagem laparoscópica, observou-se redução da disfunção pulmonar e conseqüente redução das complicações pós-operatórias que com a técnica aberta atingia taxas de $30 \%{ }^{10}$ superiores ao encontrado nesta casuística $(6,67 \%)$.

Quando comparado o tempo médio de anestesia, observou-se redução significante do tempo nos últimos 30 casos (160 minutos) quando comparados com a inicial (255 minutos).

A ocorrência de fístulas cervicais tem sido descrita quando empregada a esofagectomia por laparotomia e cervicotomia em 20,3\% (8,2\% a 37,5\%) e as estenoses tardias habitualmente dilatáveis não difere significantemente com a abordagem laparoscópica (3,34\%) ou aberta $(10 \%)^{10}$.

Tem sido descrito um aumento na incidência de disfonia transitória com abordagem laparoscópica transhiatal (25\%-66,6\% $)^{19}$. Observou-se, em nosso serviço, aumento da disfonia na técnica transhiatal laparoscópica. Este aumento quando comparada com a abordagem cervico-abdominal $(4,8 \%)$ provavelmente pela maior manipulação local da região cervical pela qual é feita a secção do esôfago e extração da peça cirúrgica, habitualmente de grande volume. Notou-se ainda, redução da disfonia nos últimos 30 casos $(6,67 \%)$ quando comparados com o início da casuística (23,3\%).

A disfagia na ausência de estenose da anastomose esofagogástrica é totalmente abolida pela esofagectomia subtotal e com cuidado de manter a anastomose esôfago-gástrica na região cervical, de pressão positiva, diminui-se a intensidade do refluxo gastroesofágico e a conseqüente esofagite do coto esofágico, principalmente nos casos em que o piloro é preservado e o refluxo duodeno-gástrico é menor.

Os resultados observados na presente série, empregando esofagectomia transhiatal laparoscópica, evidenciaram ser esta técnica factível, segura e com excelentes resultados pós-operatórios. 


\begin{abstract}
Objectives: We studied and demonstrated that the technique of subtotal esophagectomy, through laparoscopic and transmediastinal access, in order to prepare the stomach, to dissect the abdominal and thoracic esophagus, and to perform a left cervicotomy for esophageal removal and to proceed with an esophagogastric anastomosis is a good choice and it is a safe method for advanced megaesophagus treatment. Methods: Sixty transhiatal esophagectomies by laparoscopy were performed between September 1996 and December 2006, with preservation of the vagus nerve in the last ten cases. The mean age of the patients was 56.4 yearsold (18-76) and they were submitted to preoperative blood tests for T. Cruzi, esophagography, high-resolution digestive endoscopy, electromanometry, biliary ultrasound, and 24-hour ph-metry. Also a nutritional evaluation, respiratory physiotherapy and enteral nutritional support, using a nasoenteral tube were done. The indications for this surgery were radiologically and functionally advanced megaesophagus, recurrence of megaesophagus after surgery involving the esophageal junction and association of severe dysplasia and/or neoplasia. The follow-up period was from six to 118 months. Results: There was no mortality, the mean surgery time was 160 minutes (110 to 325), and improvement was noted in all evaluated parameters. Twelve of 60 (20\%) patients presented with complications; eight cases had hemopneumothorax (13.33\%); three cases had gastric stasis (5\%); four cases had cervical fistulae (6.67\%), and resolution was achieved with non operative treatment; nine cases had dysphonia (15\%). Conclusion: The results observed in laparoscopic transhiatal esophagectomy were encouraging. They demonstrated that this is a practical and safe technique with excellent postoperative results.
\end{abstract}

Key words: Megaesophagus. laparoscopy. esophagectomy.

\section{REFERENNCIAS}

1. Crema E, Cruvinel LAF, Werneck AM, Oliveira RM, Silva AA. Correlação manométrico-radiológica e sua importância no tratamento cirúrgico do megaesôfago chagásico. Rev Soc Bras Med Trop. 2003; 36(6):665-9.

2. Brücher BL, Stein HJ, Bartels $H$, Feussner $H$, Siewert JR. Achalasia and esophageal cancer: incidence, prevalence and prognosis. World J Surg. 2001; 25(6):745-9.

3. Crema E, Madureira AB, Lima VGF, Castro AMV, Silva AA, Junqueira IS. Estudo da microflora do megaesôfago chagásico. Rev Soc Bras Med Trop. 2002; 35(1):39-42.

4. Zhu LZ, Su XL, Chen KN, Yang RJ, Xing HP, Cui JG, Ke Y. [Detection rate of human papillomavirus 16 in esophageal squamous cell carcinoma from different Chinese population]. Ai Zheng. 2005; 24(7):870-3.

5. Murta EFC, Souza MAH, Lombarde W, Borges LS. Importância da infecção pelo papilomavírus humano na incidência da neoplasia intra-epitelial cervical. J Bras Ginecol. 1997; 107(10):361-6.

6. König F, Krekeler G, Hönig J, Cordon-Cardo C, Fischer G, Korabiowska M. Relation between human papillomavirus positivity and p16 expression in head and neck carcinomas-a tissue microarray study. Anticancer Res. 2007; 27(1A): 283-8.

7. Ferreira-Santos R. Tratamento cirúrgico da aperistalse esofágica (megaesôfago) [dissertação]. Ribeirão Preto (SP): Universidade de São Paulo; 1963.

8. Pinotti HW, Zilberstein B, Pollara W, Raia A. Esophagectomy without thoracotomy. Surg Gynecol Obstet. 1981; 152(3):344-6.

9. Pinotti HW, Ellenbogen G, Rodrigues JG, Raia A. Surgical treatment of the megaesophagus. Chir Gastroent. 1997; 11(1):7-14.

10. DePaula AL, Hashiba K, Ferreira EAB, de Paula RA, Grecco E. Laparoscopic transhiatal esophagectomy with esophagogastroplasty. Surg Laparosc Endosc. 1995; 5(1):1-5.

11. Crema E, Ribeiro LB, Juverson AT, Silva AA. Laparoscopic transhiatal subtotal esophagectomy for the treatment of advanced megaesophagus. Ann Thorac Surg. 2005; 80(4):1196-201.

12. De Oliveria LC, Nascimento RS, Rocha A, Gonçalves EG, da Silva JM, de Oliveira VA et al. Colelitíase em chagásicos crônicos. Arq Gastroenterol. 1997; 34(4):222-6.
13. Rocha A, Almeida H, Teixeira VPA, Silva AM. Prevalência da colelitiase em chagásicos crônicos necropsiados no Triangulo Mineiro - correlação com o megaesôfago, o megacolon e a insuficiência cardíaca. Arq Gastroenterol. 1985; 22(1):3-6.

14. Pinotti HW, Felix VN, Zilberstein B, Cecconello I. Surgical complications of Chaga's disease: megaesophagus, achalasia of the pylorus, and cholelithiasis. World J Surg. 1991; 15(2):198-204.

15. Rezende JM, Lauar KM, Oliveira AR. Aspectos clínicos e radiológicos da aperistalse do esôfago. Rev Bras Gastroenterol. 1960; 12(2):247-62.

16. Herbella FAM, Del Grange JC, Lourenço LG, Mansur NS, Haddad CM. Resultados tardios da operação de Heller associada à fundoplicatura no tratamento do megaesôfago: análise de 83 casos. Rev Assoc Med Brasil. 1999; 45(4):317-22.

17. Loviscek LF, Cenoz MC, Badaloni AE, Agarinakazato O. Early cancer in achalasia. Dis Esophagus. 1998; 11(4):239-47.

18. Swanstrom LL, Hanson P. Laparoscopic total esophagectomy. Arch Surg. 1997; 132(9):943-7; discussion 947-9.

19. Pinotti HW, Cecconello I, Rocha JM, Zilberstein B. Resection for achalasia of esofagus. Hepatogastoenterology. 1991; 38(6):470-3.

Recebido em 29/08/2008

Aceito para publicação em 13/11/2008

Conflito de interesse: nenhum

Fonte de financiamento: nenhuma

\section{Como citar esse artigo:}

Crema E, Ribeiro LPB, Sousa RC, Terra Júnior JA, Silva BF, Silva AA, Silva AV. Esofagectomia transhiatal laparoscópica para o tratamento do megaesôfago avançado - análise de 60 casos. Rev Col Bras Cir. [periódico na Internet] 2009; 36(2). Disponível em URL: http://www.scielo.br/ $\mathrm{rcbc}$

Endereço para correspondência:

E-mail: cremauftm@mednet.com.br 